\title{
Как сохранить географическое пространство Азиатской России?
}

А.К. тулохонов, академик РАН, Байкальский институт природопользования СО РАН, Улан-Удэ. E-mail: aktulohonov@binm.ru

В статье географическое пространство России рассматривается в свете последних политических и социально-экономических процессов. Автор акцентирует внимание на географических аспектах пространственного развития азиатской части России, ограниченной с севера российской Арктикой, с юга-приграничьем с Казахстаном, Монголией и Китаем. Отмечено, что в существующих стратегических документах РФ недостаточно оцениваются риски климатических изменений, смены политического, экономического курса южных соседей Российской Федерации. Рассмотрены ключевые достоинства и недостатки мегапроекта «Единая Евразия - Транс-Евразийский пояс развития», проанализированы отдельные аспекты Программы северного экономического коридора, принятой лидерами России, Монголии и Китая. Сформулированы концептуальные предложения по сохранению географического пространства Азиатской России.

Ключевые слова: географическое пространство, Азиатская Россия, стратегия пространственного развития, Северный экономический коридор

Политические события последних лет, ознаменовавшиеся событиями в Крыму и на Украине, западными экономическими санкциями резко обострили тему политической географии. Назрела необходимость разработки стратегии сохранения и освоения российского пространства, отвечающей современным вызовам. Задача создания такого документа сформулирована в федеральном законе «О стратегическом планировании в РФ» ${ }^{1}$. На данный момент в целом одобрена концепция новой Стратегии пространственного развития Российской Федерации на период до 2030 г,, где впервые на государственном уровне утверждается необходимость рационального использования огромных пространств нашей страны ${ }^{2}$.

\footnotetext{
${ }^{1}$ Федеральный закон от 28 июня 2014 г. №172-Ф3 «О стратегическом планировании в Российской Федерации» [Эл. ресурс]. URL: http://base.garant.ru/70684666 (дата обращения: 22.08.2018).

${ }^{2}$ Проект Концепции Стратегии пространственного развития Российской Федерации на период до 2030 года [Эл. ресурc]. URL: http://xn-7sbbhnbqiallebd4mma.xn-plai/ uploadedFiles/files/Kontseptsiya_SPR.pdf (дата обращения: 22.08.2018).
} 
В этой связи необходимо по-новому взглянуть на роль России в геополитических процессах на всем Евроазиатском континенте, а учитывая растущую роль Азиатско-Тихоокеанского региона на глобальной мировой арене, в первую очередь оценить возможности развития нашей азиатской периферии в условиях рыночной экономики. Географическое положение Сибири и Дальнего Востока создает равные возможности для торговых отношений как с европейскими странами, так и со странами АТР, что позволяет сократить потери от западных экономических санкций. Однако в условиях глобализации и появления новых транзитных маршрутов, географический фактор сам по себе достаточно неустойчив, и нам важно научиться его использовать с наибольшей выгодой, в том числе - в интересах будущих поколений.

Между тем низкие темпы роста большинства экономических показателей России, рост инфляции и числа населения с доходами ниже прожиточного минимума, свидетельствуют о необходимости коренных изменений в социальной политике государства, которые были частично обозначены в очередном обращении Президента РФ В.В. Путина Федеральному собранию ${ }^{3}$ и его новом майском Указе 4 .

\section{Российское пространство в современных политических и социально-экономических реалиях}

К сожалению, социально-экономические процессы последних десятилетий не способствуют гармоничному развитию географического пространства страны.

С начала демократических реформ значительно сократилось население России. Происходит концентрация населения и производства в крупных городах и запустение периферии. Катастрофически уменьшается количество сельских населенных пунктов, поселков городского типа. В 63 российских регионах с 2000 г. по 2014 г. сократилась численность населения. Если в 1994 г. 10 передовых регионов производили в совокупности $41,4 \%$ ВРП,

\footnotetext{
${ }^{3}$ Послание Президента Федеральному собранию - 1 марта 2018 г. [Эл. ресурс]. URL: http://kremlin.ru/events/president/news/56957 (дата обращения: 22.08.2018).

${ }^{4}$ Указ Президента «О национальных целях и стратегических задачах развития Российской Федерации до 2024 года» [Эл. ресурс]. URL: http://kremlin.ru/events/president/ news/57425 (дата обращения: 22.08.2018).
} 
то в 2017 г. на их долю приходится уже 53\%. На Москву и Московскую область, где нет каких-либо значимых добывающих или обрабатывающих производств, площадь которых составляет 0,27\% территории РФ, по статистике приходится 13\% населения, 26,3\% всей промышленной продукции и самый большой объем экспорта в России.

Несмотря на огромную протяженность транспортных магистралей, транзит через территорию России не превышает 1\% товарооборота между Европой и Азией, всего же используется менее 5\% транзитного потенциала страны [Транспортные.., 2018].

Только с 2012 г. по 2017 г. долги российского населения за жилищно-коммунальные услуги выросли со 104 до 645 млрд руб., что лучше любого индикатора отражает экономическое состояние общества.

В условиях плановой экономики СССР были приложены огромные усилия для развития азиатской части страны, которая и поныне является основным источником экспортных поступлений в российский бюджет. Но после развала Советского Союза экономика восточных территорий пострадала в первую очередь. Резкое сокращение рабочих мест, падение уровня жизни в Сибири и на Дальнем Востоке обусловили массовый отток населения в центральную часть страны. Разрушительными для периферии оказались и последние реформы в области образования и здравоохранения. Единый госэкзамен «вымывает» из сел в областные центры и далее в столицу талантливую молодежь, которая обратно уже не вернется, и очень часто вслед за детьми уезжают их родители. Закрытие в селах малокомплектных школ вынуждает население покидать эти места. Вузовское образование в Сибири и на Дальнем Востоке тоже сокращается, не выдерживая конкуренции с центральными университетами. Социологические опросы показывают, что более 95\% населения оценивают состояние российского здравоохранения как неудовлетворительное, то же самое относится и к образованию.

Наметившееся в последние годы сокращение миграционного оттока из периферийных регионов, которое наши руководители выдают за положительный результат многочисленных реформ, особого оптимизма не вызывает. По всей видимости, почти все, кто мог, уже уехали, активной молодежи, готовой 
искать лучшую долю «подальше от родимой земли», почти не осталось.

Последние надежды на сохранение демографического потенциала российской периферии исчезли после выполнения «майских» (2012 г.) указов Президента в части повышения оплаты труда в бюджетной сфере, привязанного к региональным нормативам. Дифференциация в заработной плате между селом и городом, периферией и столицей в результате лишь увеличилась. При этом была полностью разрушена система районных коэффициентов, которая в советский период привлекала и удерживала квалифицированных специалистов на работе в удаленных регионах Сибири и Дальнего Востока.

На взгляд автора, за годы реформ экономические потери периферии от «выдавливания» ее интеллектуального потенциала многократно превысили доходы от экспорта углеводородов. Но, что хуже всего, такой подход лишает российскую глубинку перспектив развития.

Министерство сельского хозяйства в погоне за валовыми показателями уделяет внимание только поддержке крупных агрохолдингов, что в конечном итоге отрицательно влияет на жизнь основной массы сельских товаропроизводителей. Более того, льготы тем же олигархическим структурам на приобретение зарубежных семян, продуктивных пород скота, новой импортной техники и технологий, налоговые послабления на экспорт зерновых усиливают зависимость аграрного сектора экономики от внешних факторов и подрывают продовольственную безопасность России.

Необходимы коренные изменения в управлении экономикой страны, разработка более эффективных подходов, определяющих будущее России в новых геополитических и социально-экономических обстоятельствах. Огромная территория российского государства не может развиваться по единым законам и правилам, экономическая политика должна быть дифференцирована с учетом природных условий, национального состава, географического положения, этно-культурных и других особенностей, которые должны быть встроены в Стратегию пространственного развития Российской Федерации. 


\section{О Стратегии пространственного развития Российской Федерации}

Необходимо отметить, что обсуждаемый документ (далее Стратегия) не есть стратегия социально-экономического развития страны и его отдельных регионов. Согласно утвержденной концепции, более всего в своей целевой установке Стратегия должна быть направлена на создание единого социума на территории огромной страны с общими идеологическими, этнокультурными, интеллектуальными и другими ценностями для вхождения России в число наиболее передовых в научно-технологическом отношении государств мира и сохранения ее территориальной целостности. В определенной степени эти установки напоминают Конституцию Советского Союза, в которой были поставлены задачи создания нового общества - советского народа, который победил в Великой Отечественной войне, первым вышел в космос и создал ядерный щит. К сожалению, этому народу не очень повезло с реформами, затеянными в эпоху социальнополитических перемен.

При разработке Стратегии необходимо учитывать не только масштабы страны и ее национальную специфику, суровые природно-климатические условия на большей части территории, и т.д. На своих сухопутных границах Россия соседствует с 16 государствами, представляющими все основные мировые религии, все этапы и формы социально-экономического развития. Поэтому ее будущее не может рассматриваться в замкнутом территориальном пространстве без учета политических и социально-экономических процессов, происходящих по ее периферии [Приграничные..., 2010].

В проекте Концепции Стратегии, утвержденном в 2017 г., впервые акцентируются новые вызовы пространственному развитию страны, в том числе:

- беспрецедентный центростремительный вектор и сжатие экономического пространства;

- невиданные контрасты межрегионального экономического развития;

- геополитическая нестабильность на новом приграничье РФ;

- коммуникационный разрыв между восточными и западными территориями; 
- унификация федерального законодательства в пользу центра, монополия госсобственности и формальный федерализм государственного устройства.

В этом же документе названы риски долгосрочного пространственного развития государства, из которых особо выделяются следующие:

- проблема долгосрочного ухудшения конкурентных позиций опорных регионов в результате научно-технологического отставания от ведущих стран в темпах модернизации экономики;

- реализация проектов альтернативных международных транспортных коридоров в сопредельных странах, снижающих привлекательность транзитного потенциала России;

- увеличение частоты стихийных бедствий в результате происходящих климатических изменений.

Каждый из этих вызовов нуждается в особом внимании и детальном научном обосновании. В рамках этой статьи автор делает акцент на географических аспектах пространственного развития Азиатской России, в первую очередь на оценке ситуации на ее северных и южных границах.

Как правило, Российскую Арктику экономисты рассматривают как крупнейший источник углеводородного сырья. Однако последние климатические катастрофы в Северном полушарии с небывалой жарой, наводнениями и экстремальными снегопадами следует считать первыми предвестниками будущих природных катаклизмов, природа которых связана с таянием льдов Северного Ледовитого океана.

Если ранее при сплошном ледовом покрове с высоким альбедо основная часть солнечной энергии отражалась от его поверхности без особых последствий, то теперь темная водная масса поглощает больше тепла и, нагреваясь, вызывает дальнейшее таяние льдов. И этот процесс во времени ускоряется. Глобальное потепление приводит к перемещению теплых атмосферных масс из Арктики на континент, сокращению многолетней мерзлоты, общей аридизации климата и другим негативным явлениям, последствия которых еще не известны.

Между тем после распада Советского Союза и реформ академической науки научные исследования Арктики оказались сведены к минимуму. Сжалась сеть климатических мониторинговых 
станций в арктической зоне, сократился парк исследовательских судов. Ряд международных организаций предлагает приоритет морепользования в арктических и антарктических водах отдавать государствам, вкладывающим ресурсы в научные программы изучения полярных океанов. В этом случае Россия, которая отказалась в 2015 г. от финансирования программы «Мировой океан» и постоянно реформирующая свою науку не в пользу повышения ее эффективности, теряет свой авторитет в Арктике и Антарктике. Воистину скупой платит дважды.

Ситуация на южном приграничье Азиатской России также далека от оптимистичной. На всей территории Средней Азии активизируются процессы исламизации, а переход алфавита во все еще «братских» республиках с кириллицы на латиницу - уже свершившийся факт. С неизбежной сменой политического руководства можно смело прогнозировать возможность изменения политического курса южных соседей. Однако ни в одном федеральном документе найти хотя бы упоминание о возможности возникновения такого риска не удалось.

Один из наиболее известных американских политологов 3. Бжезинский, еще два десятилетия назад предупреждал: «Для русских спектр потенциального конфликта с мусульманскими государствами по всему южному флангу России (общая численность населения которых вместе с Ираном, Турцией и Пакистаном составляет более 300 млн человек) представляет собой источник серьезной обеспокоенности» [Бжезинский, 2018]. Как известно, его прогнозы имеют привычку сбываться. При этом отметим, что сухопутная граница России с Казахстаном на протяжении более 7 тыс. км не имеет должного пограничного обустройства и естественных преград.

Другое бросающееся в глаза упущение - после распада Coветского Союза руководство новой России практически «забыло» о существовании ближайшего соседа - Монголии, где некогда находился самый большой советский военный контингент и огромное количество гражданских специалистов, создававших в этой стране многочисленные промышленные и гражданские объекты. В современных политических документах, определяющих наши отношения в Азии, эта страна часто остается без должного внимания. В Указе Президента РФ «О мерах 
по реализации внешнеполитического курса РФ» ${ }^{5}$ Министерству иностранных дел совместно с другими органами исполнительной власти предписано:

«...в Азиатско-Тихоокеанском регионе:

- углублять равноправное доверительное партнерство и стратегическое взаимодействие с Китайской Народной Республикой, стратегическое партнерство с Республикой Индией, Социалистической Республикой Вьетнам, развивать взаимовыгодное сотрудничество с Японией, Республикой Корея, Австралией, Новой Зеландией и другими ключевыми государствами АзиатскоТихоокеанского региона...». Преднамеренно или нет, Монголия в этом важном документе не упоминается. Не улучшает наши отношения с южным соседом и экологический конфликт в связи со строительством гидростанций на монгольской части бассейна реки Селенга - основного притока озера Байкал.

Вообще следует отметить, что водные ресурсы истоков Обь-Иртышского, Байкало-Енисейского и Амурского речных бассейнов, расположенные на территориях Китая, Казахстана, Монголии, активно используются этими странами при добыче нефти, развитии горнорудной промышленности, сельского хозяйства. Это уже создает проблемы водопользования на российской территории, а в условиях общей аридизации климата можно предположить, что конфликты вокруг использования водных ресурсов трансграничных рек здесь, как и во всем мире, будут только нарастать. Этот фактор нельзя не учитывать в стратегических планах пространственного развития страны.

\section{Транспортно-логистическая инфраструктура в реализации Стратегии}

Создание территориальной целостности российского государства невозможно без развития существующих транспортно-логистических, коммуникационно-информационных, энергетических коридоров и обеспечения равной доступности к ним населения удаленных регионов Сибири и Дальнего Востока, в том числе за счет прямых внутрирегиональных контактов, минуя европейский центр. При этом принципиально важно максимально

\footnotetext{
5 Указ Президента Российской Федерации от 7 мая 2012 г. № 605 «О мерах по реализации внешнеполитического курса Российской Федерации». [Эл. ресурс]. URL: http:/www.garant.ru/hotlaw/federal/396370/ (дата обращения: 22.08.2018).
} 
использовать транзитное положение российской территории между Европой и Азией.

Поэтому новым «майским» (2018 г.) Указом Президента РФ 6 предписано Правительству РФ разработать и утвердить до 1 октября 2018 г. комплексный план модернизации и расширения магистральной инфраструктуры, предусматривающий обеспечение в 2024 г:

a) развитие транспортных коридоров «Запад - Восток» и «Север - Юг» для перевозки грузов (в том числе за счет строительства и модернизации российских участков автодорог, относящихся к международному транспортному маршруту «Европа - Западный Китай»);

б) повышение уровня экономической связанности территории РФ посредством расширения и модернизации всех видов транспорта... (в том числе создания сети авиационного сообщения, где до 50\% маршрутов должны миновать столицу).

Многие ведущие российские экономисты считают, что будущее России в значительной мере будет определяться реализацией мегапроекта «Единая Евразия - Транс-Евразийский пояс развития» (ТЕПР), идеология которого прозвучала в обращении Президента В. В. Путина Федеральному собранию РФ, обсуждалась на Совете Безопасности РФ и в докладах Интеграционного клуба при председателе Совета Федерации. При этом акцентируется внимание на возможностях активизации экономических связей по маршруту Европа - Восточная Азия за счет создания трансконтинентальной транспортной системы нового поколения.

В настоящее время более 90\% грузов из стран Азиатско-Тихоокеанского региона достаточно отчетливо специализированы на морской транзит. Другая часть перевозок нарастающим потоком идет в Европу через Западный Китай, Казахстан и Белоруссию. Так, на экономическом форуме в Боао (Китай) в апреле 2018 г. было отмечено, что за последние годы объем контейнерных перевозок через Казахстан вырос почти в 200 раз, и в 2020 г. достигнет 2 млн контейнеров. Уже сегодня две трети всех взаимных поставок из ЕС в Китай идут через казахстанскую границу [Винокуров, 2018. С. 25-26]. При этом обработка

${ }_{6}^{6}$ Указ Президента Российской Федерации от 07.05.2018 г. № 204 «О национальных целях и стратегических задачах развития Российской Федерации на период до 2024 года» [Эл. peсурс]. URL: http://kremlin.ru/acts/bank/43027/page/1 (дата обращения: 27.08.2018). 
грузов на казахстанской таможне обходится в 5-8 раз быстрее и дешевле, чем на ст. Забайкальск.

Таким образом, мегапроект «Единая Евразия» вовлекается в жесткую конкуренцию глобальных транспортных систем и для того, чтобы он состоялся, его необходимо встроить в уже действующую структуру транзитных перевозок «Восток - Запад» или предложить очень весомые аргументы в его пользу. В этой связи наибольшую актуальность приобретает не увеличение пропускной способности Транссиба или БАМа, а поиск ответа на вопрос - что и куда возить и за какие деньги?

Казалось бы, ответ должен быть очевиден - использовать открывающиеся возможности для экономического развития прилегающих к транспортному коридору регионов. Между тем у России существуют серьезные проблемы с реализацией программы развития Дальнего Востока и Байкальского региона. Практически провалена программа сотрудничества приграничных регионов России и Китая, подписанная главами государств в 2009 г.

Несмотря на это, китайская сторона по-прежнему заинтересована в освоении месторождений стратегических полезных ископаемых в Забайкалье, в первую очередь вдоль планируемой железной дороги Новоильинск - Уоян (Таксимо). В этом случае за счет китайских инвестиций вполне реально строительство центральной хорды, соединяющей Транссиб и БАМ, что может инициировать старт строительства Мокской ГЭС, освоение Удокана, Сынныра и других природных богатств вдоль магистрали.

Большое внимание в планах мегапроекта «Единая Евразия» уделяется также развитию Северного морского пути и речного сообщения с Арктикой. В этой связи следует отметить, что прогрессирующее таяние льдов Северного Ледовитого океана позволяет торговым судам, следующим от Берингова пролива в Северную Европу (в Роттердам), миновать Арктику в высоких широтах за пределами экономической зоны РФ, значительно сокращая при этом протяженность маршрута. Первые перевозки китайских контейнерных грузов прошли в Европу таким путем уже в 2016 г. Однако отметим, что такие маршруты снижают потребность ледокольного сопровождения и обслуживания транзитных судов в российских арктических портах на трассе Северного морского пути.

В свою очередь глобальное потепление и аридизация климата в истоках сибирских рек отрицательно влияют на их 
энергетический и судоходный потенциал (это уже реально ощущается в бассейне озера Байкал). А это ставит под угрозу существующие планы развития речного сообщения южных регионов Сибири с арктическими портами.

Из других «упущений» мегапроекта отметим, что при его обсуждении практически не затрагивается тема обеспечения огромной части страны в северных широтах и в сельской местности обычной радиосвязью. Закрытие большинства радиопередающих станций, работавших на длинных и средних волнах, привело к тому, что даже в Бурятии значительная часть районных центров не имеет доступа к «Радио России» и слушает новости китайских и корейских источников, вещающих на русском языке. Ушли в прошлое и проводные радиоприемники, еще совсем недавно круглосуточно передававшие новости.

\section{Северный экономический коридор как альтернатива Великого шелкового пути}

Вышеописанная не слишком благоприятная для России политическая, экономическая и климатическая ситуация должна стимулировать российское руководство к поиску путей минимизации подобных угроз. На наш взгляд, в этих условиях особое значение приобретает строительство южной ветви Евразийского транспортного коридора по маршруту Центральный Китай - Монголия - Транссиб, обозначенного в соглашении глав трех государств 2016 г. как Программа создания экономического коридора Китай - Монголия - Россия ${ }^{7}$ (Северный экономический коридор, СК). Программа из семи крупных разделов включает практически все направления международного сотрудничества и содержит перечень из 32 технических проектов, включающих совместное развитие транспортной инфраструктуры, сотрудничество в области промышленности, энергетики, торговли, таможенного дела, охраны окружающей среды и др.

На наш взгляд, реализация СК может придать новый стимул для развития внешней торговли сибирской экономики. Сегодня по объему валового регионального продукта (10,4\% от общероссийского показателя) СФО значительно превосходит показатели

\footnotetext{
${ }^{7}$ Программа создания экономического коридора Китай-Монголия-Россия [Эл. ресурс]. URL: http://minpromtorg.govrb.ru/rus-ch-mn.pdf(дата обращения: 22.08.2018).
} 
Дальневосточного региона (5,7\%), но по объему внешнеторгового оборота в связи с удаленностью от международных рынков сбыта значительно уступает не только Дальнему Востоку (соответственно $37 \%$ и 48,1\%), но и среднероссийскому уровню $(54,5 \%)$.

Между тем проект северного коридора может быть интересен не только для России, ведь он представляет собой кратчайший маршрут между центральным Китаем и Европой. Если восточные провинции КНР в своих торговых отношениях ориентированы прежде всего на порты Тихоокеанского побережья, а для западных более выгодна торговля по Шелковому пути, то открывающийся в рамках СК транзит через Монголию предоставляет новые возможности для северного и центрального Китая, получающих кратчайший выход на российский и европейский рынки. Вполне понятны выгоды развития экономических отношений с двумя сильными соседями и для Монголии. Таким образом, в этом проекте соединяются интересы трех крупнейших стран юго-восточного региона.

Однако необходимо понимать, что «заказывает музыку» тот, кто платит. Только для реализации ключевых транспортных проектов Фонд Шелкового пути выделяет более 40 млрд долл., особое финансирование выделено и для китайской академии наук с целью научных исследований вдоль зоны СК. Для того, чтобы Россия могла сполна использовать представляющиеся шансы для реализации своих геополитических, экономических и гуманитарных интересов в рамках мегапроекта, она должна выявить эти интересы на самых ранних этапах, до возникновения возможных противоречий.

Прежде всего, Северный экономический коридор является конкурентом Шелкового пути в части грузового транзита в транспортной системе «Восток - Запад». Плюс в том, что, в отличие от формируемого маршрута по Шелковому пути через Западный Китай и Казахстан, здесь уже существует действующий транспортный канал, включающий автомобильный и железнодорожный транспорт с выходом на Транссибирскую, а в перспективе - и на Байкало-Амурскую магистраль. Безусловным преимуществом Северного экономического коридора является и минимальное количество пересечения таможенных пунктов, и безопасность грузов. Последнее соображение особенно актуально при обсуждении южного вектора Шелкового 
пути, который, согласно ряду программных документов, должен пройти южнее Каспийского моря через Иран и Турцию. На наш взгляд, в условиях политической нестабильности Передней Азии подобный маршрут не имеет особых перспектив.

Однако для того, чтобы реально претендовать на крупные объемы международных перевозок по Северному коридору, необходимо провести коренную модернизацию железнодорожных и автомобильных трасс от Транссиба через Монголию и до Центрального Китая. В настоящее время одноколейный путь на дизельной тяге, проходящий по монгольской территории, физически и морально устарел. Кроме того, принципиально важным остается вопрос о строительстве в Монголии новой железной дороги Эрлянь - Наушки, в которой интересы Китая и России диаметрально противоположны - каждая из сторон заинтересована в прокладке своей стандартной колеи. В свою очередь Правительство Монголии рассчитывает, что ввод в эксплуатацию северного железнодорожного коридора позволит ввести в экономический оборот месторождения аймаков Хувсгел, Булган и Орхон, а также увеличить поток туристов и придать дополнительный импульс социально-экономическому развитию страны.

Кроме того, интересы всех трех стран пересекаются в проекте развития автомобильного и железнодорожного маршрута Пекин-Улан-Батор-Улан-Удэ-Москва, который представляет собой кратчайшее расстояние между Китаем и Европой в мегапроекте «Один пояс - один путь». На наш взгляд, России следовало бы четче обозначить свои позиции в этом проекте, поскольку монгольский экспортный транзит в перспективе может увеличить грузопоток в направлении ее дальневосточных морских портов. При этом нужно иметь в виду, что в настоящее время активизируются каналы вхождения в экономику Монголии исламского капитала с целью ее ориентации в сторону мусульманской части Западного Китая. Одним словом, для защиты своих интересов в регионе России необходимо учитывать все возможные факторы политического и экономического сотрудничества с Монголией.

В завершение этого раздела статьи отметим, что для реализации директив Президента РФ В.В. Путина о приоритетном освоении экономического пространства Сибири и Дальнего Востока принципиально важны не просто транзитные перевозки, а более всего создание вдоль транспортных коридоров промышленно-аграрных 
кластеров, которые должны стать базой для усиления экспортного потенциала России в торговле со странами АТР. Пока же Россия не может обеспечить даже координацию (не говоря уже о государственном планировании) в организации работы железнодорожного, автомобильного и трубопроводного транспорта. Вместо решения государственных задач отраслевые корпорации и частные компании решают свои локальные проблемы, нередко вступая друг с другом в конкуренцию, не обращая никакого внимания на интересы и потребности клиентов - производителей, потребителей и перевозчиков, нарушая пропорции классической триады транспортной экономики: скорость, стоимость и сохранность грузов.

\section{Исторические уроки в настоящем: механизмы и риски сохранения географического пространства России}

Начиная с Александра Первого, затем - под руководством С.Ю. Витте и П.А. Столыпина российское государство обращало особое внимание на развитие своих восточных территорий и достаточно успешно достигало положительных результатов [Тулохонов, 2012]. Становление экономики Советского Союза также во многом было результатом реализации плановых мероприятий по укреплению экономического пространства его восточных рубежей. Причем - в условиях жесткого лимита всех ресурсов, дефицита профессиональных кадров, экономической изоляции и военной конкуренции с НАТО. Многими поколениями государственных деятелей была отработана система политических, экономических и моральных факторов привлечения на Восток трудовых ресурсов, повышения производительности их труда.

Как показывает исторический опыт, масштабные проекты развития производительных сил восточных территорий страны не могут ограничиваться обсуждением только транспортных проблем, но должны сопровождаться системной оценкой глобальной экономической ситуации, анализом выполнения всех прошлых и действующих директив, включая федеральные целевые программы, изучением всего предшествующего позитивного и негативного опыта реализации крупных промышленных объектов.

Россия с ее разнообразием природных условий и огромной протяженностью территории должна иметь адаптивные способы управления ее экономикой. Природа не имеет административ- 
ных границ, и, на наш взгляд, России сегодня необходимо новое экономико-географическое районирование территории с учетом рыночных реалий, с выделением природной и социальной специфики каждого региона. При этом каждый субъект Федерации своей экономикой, интеллектуальным потенциалом, культурой, ресурсами, географическим положением должен как «пазл» войти в общие интересы государства. Такая мозаика и должна стать основой пространственного единства российского государства. Пока же эффективность государственного управления в России, увы, далека от оптимальной.

Прежде всего, как отметил глава государства на заседании возглавляемого им Попечительского совета Русского географического общества, наши чиновники и дипломаты слабо знакомы с географией․ Возможно, по этой причине федеральные округа оказались «нарезаны» произвольно. В результате Тюменская область вошла в Уральский федеральный округ, а Якутия в Дальневосточный. Нет научного обоснования и объективности в определении южной границы Российской Арктики и, соответственно, северных коэффициентов. Остается открытым вопрос отнесения Чукотки и Якутии к Арктике или Дальнему Востоку. Росчерком пера с карты страны исчезли пять автономий на Урале, в Сибири и на Дальнем Востоке, что стало дополнительной причиной сокращения работников бюджетной сферы на этих территориях [Тулохонов, 2017. С. 17-21].

Вторая наша беда - нерациональное использование бюджетных средств. Как правило, в качестве главного аргумента провала большинства планов экономического развития правительство приводит дефицит бюджета. Между тем, недавняя история становления Советского государства свидетельствует о том, что и в более тяжелых условиях находились возможности для строительства ДнепроГЭСа, Магнитки, авиационных заводов в Сибири и на Дальнем Востоке, Байкало-Амурской магистрали...

В поисках дополнительных финансовых ресурсов правительство повышает пенсионный возраст, налоги, цены на топливо и ЖКХ, но вместе с тем упорно сопротивляется введению прогрессивного налогообложения, налога на роскошь. Более того,

824 апреля 2017 года Владимир Путин провел заседание Попечительского совета Русского географического общества [Эл. ресурс]. URL: http://kremlin.ru/events/president/ news/54363 (дата обращения: 27.08.2018). 
постановлением Правительства ${ }^{9}$ были внесены изменения в порядок публикации данных о заработках топ-менеджеров компаний с госучастием и членов их семей. Эти сведения фактически были засекречены от широкой общественности. В бюджете нашлись немалые средства на увеличение содержания парламентских партий и административного аппарата, которые уже давно превзошли масштабы бюрократии советского периода; особой статьей проходят огромные расходы на проведение политических и зрелищных мероприятий, подобных форуму АТЭС, Олимпийских игр, различных чемпионатов, универсиад; обсуждается решение о проведении в России очередных Олимпийских игр и Всемирной выставки. Всё это свидетельствует о том, что ресурсы в стране имеются, вопрос только в их рациональном использовании и контроле.

Третьей проблемой, как нам представляется, является отсутствие коллегиальности в руководстве страны. Это приводит к тому, что многие высокие директивы чуть ли не в открытую саботируются правительственными чиновниками, а решение некоторых вопросов порой требует прямого вмешательства Президента. Ни в одной демократической стране мира нет такого «ручного» управления экономикой. Даже в СССР наиболее важные решения принимались большинством членов Политбюро, такая же система существует в настоящее время в Китае.

Четвертая по порядку, но не по значению управленческая проблема - отстранение от процесса принятия решений экспертного сообщества. При таких огромных масштабах страны разработка, принятие и выполнение государственных директив должны иметь необходимое научное обоснование, альтернативные пути предлагаемых решений, не исключая и крайних вариантов. Не случайно в большинстве развитых стран существует реальная двух- или многопартийная система, которая контролирует исполнительную власть. Между тем в России законодательная власть, по сути, обслуживает исполнительные органы, в высшем звене руководства отсутствует оппозиция, а в правительстве профессионалы, прошедшие школу работы в регионах представляют собой редкое исключение.

\footnotetext{
${ }^{9}$ Постановление Правительства РФ от 25.03.2015 N276 «О внесении изменений в постановления Правительства Российской Федерации от 22 июля 2013 г. № 613 и от 18 декабря 2014 г. № 1405» [Эл. ресурc]. URL: http:/www.garant.ru/products/ipo/ prime/doc/70826992/ (дата обращения: 27.08.2018).
} 
В отличие от советского периода, в российском правительстве и парламенте практически нет представителей науки, а наиболее талантливая молодежь, не имея перспектив карьерного роста, уже три десятилетия стремится реализовать себя за границей.

На наш взгляд, сложная политическая и экономическая ситуация, в которой оказалась наша страна, сегодня как никогда требует коллегиальности в руководстве, создания специальной структуры управления пространственным развитием, восстановления некоего подобия Госплана, призванного координировать деятельность различных отраслей и ведомств в интересах государства, формирования ресурсных министерств, дающих основные бюджетные поступления, и упразднения ряда отраслевых ведомств, не актуальных в условиях частной собственности крупнейших отраслей экономики. Опыт Сингапура и других азиатских «тигров» свидетельствует о том, что в основе их успехов, помимо борьбы с коррупцией и кумовством, лежит профессионализм и опыт правительства.

При постановке социально-экономических задач по развитию пространства страны следует учитывать, что пространство это не просто географический ландшафт, но и все богатства, расположенные на поверхности земли и под ней. И ключевым механизмом для сохранения и рационального использования этих природных богатств является представление о системности окружающей среды и собственности.

Однако в Конституции РФ отсутствует понятие о региональной собственности, которая как бы входит в государственную (то есть федеральную), а все другие виды собственности на природные ресурсы не более чем декларация. Результатом такой «федеральной монополии» нередко становятся социальные конфликты и лишение регионов стимулов экономического развития. К примеру, население Прибайкалья из-за экологических ограничений лишенное прав на заготовку дров, свободный лов рыбы и даже порой - прав имущественной собственности, нередко отказывается тушить лесные пожары на федеральных землях, которые воспринимаются им как чужие. При этом многие жители вынуждены обеспечивать свое повседневное существование, по сути, криминальными способами, в нарушение экологического законодательства, что порождает серьезные психологические и даже мировоззренческие проблемы. 
В попытке закрепления населения на восточных территориях правительство принимает закон «О дальневосточном гектаре», который воспринимается как плохое подражание столыпинской реформе [Тулохонов, 2012]. Однако при наличии в стране более чем 40 млн га заброшенных бывших колхозных земель вблизи экономических центров эта инициатива представляется не более чем обреченной на провал «кампанейщиной». Важнейшей составляющей формируемой Стратегии пространственного развития, на наш взгляд, должно стать воспитание патриотизма, чувства любви к большой и малой Родине, особенно для жителей российской периферии, среди которых, к сожалению, популярны миграционные настроения. Духовные скрепы, некогда консолидировавшие советский народ, размываются ускоренными темпами. В России появилось уже не одно поколение молодежи, никогда не бывавшее в Москве на Красной площади. В программе средней школы максимально сокращено изучение истории и географии родного края, полностью исчезло краеведение, редкостью стали школьные музеи. Между тем в идеологии, как и в природе, пустоты не бывает...

Как писал академик А.Г. Гранберг [Гранберг, 2011. С. 17] «пространство - ценнейший ресурс государства для наших дней и для будущего». Оно досталось нам от предков, и мы должны передать его своим потомкам как главное условие для достойной жизни и сохранения российской государственности. При этом пространство не может быть пустым или некомфортным, и наша задача обустроить его.

\section{Литература}

Бжезинский 3. Великая шахматная доска. М.: Изд-во АСТ, 2018. 380 с.

Винокуров Е.Ю. Транспортные коридоры Шелкового пути: потенциал роста грузопотоков через ЕАЭС. / Е. Ю. Винокуров, В.Г. Лобырев, А. А. Тихомиров [и др.] / Под ред. Е. Ю. Винокурова. СПб.: ЦИИ ЕАБР, 2018. 74 с.

Гранберг А.Г. Возможны ли распад или сжатие России? // Регион: экономика и социология. 2011. № 2. С. 9-18.

Приграничные и трансграничные территории Азиатской России и сопредельных стран: Проблемы и предпосылки устойчивого развития / Отв. ред. П.Я., Бакланов, А.К. Тулохонов; Рос. акад. наук, Сиб. отд-ние, Байкальский ин-т природопользования и др. Новосибирск: Изд-во СО РАН, 2010. 606 с. (Интеграционные проекты СО РАН, вып. 23).

Транспортные коридоры Шелкового пути: потенциал роста грузопотоков через ЕАЭС. СПб.: ЦИИ ЕАБР, 2018. 74 с. 
Тулохонов А. К. Еще раз об административно-территориальном устройстве России // Экономист. 2017. № 11. С. 17-21.

Тулохонов А.К. О пророках в своем отечестве (к 150-летию П. А. Столыпина) // Вопросы экономики. 2012. № 6. С. 152-155.

Статья поступила 30.08.2018.

\section{Summary}

Tulokhonov A. K., Baikal Institute of Nature Management, SB RAS, Ulan-Ude How to Save the Geographical Space of Asian Russia?

In the article, the geographical space of Russia is considered in the light of the latest political and socio-economic processes. The author focuses on the geographical aspects of the spatial development of Asian Russia, primarily on the assessment of its northern and southern borders situation. From one side the borders are limited by the Russian Arctic, and in the south by the border with Kazakhstan, Mongolia and China. It is noted that the risks of climate change, the change in the political and economic course of Russia's southern neighbors are insufficiently assessed in the strategic documents of the Russian Federation. The key merits and demerits of the mega-project "United Eurasia - Trans-European Belt Development" are considered, and some aspects of the Northern Economic Corridor Program adopted by the leaders of Russia, Mongolia and China are analyzed. Conceptual proposals for the preservation of the geographical space of Asian Russia are formulated.

Geographical space; Asian Russia; spatial development strategy;Northern Economic Corridor

\section{References}

Bzhezinski Z. (2018) Velikaya shakhmatnaya doska [Great chess board]. Moscow, AST Publishing House. 380 p. (In Russ.)

Vinokurov E. Yu. (2018) Transportniye koridory Shelkovogo puti: potentsial rosta gruzopotokov cherez EAES [Transport corridors of the Silk Road: the potential for growth of cargo flows through the EAEU]. Ed. Vinokurov E. Yu.-St. Petersburg, CIS EADB. 74 p. (In Russ.)

Granberg A. G. (2011) Is the disintegration or reduction possible for Russia? Region: Economika I sociologia [Region: Economics and Sociology]. No. 2. Pp. 9-18. (In Russ.)

Prigranichnyye i transgranichnyye territorii Aziatskoy Rossii i sopredel'nykh stran: Problemy i predposylki ustoychivogo razvitiya [Cross-border and transboundary territories of Asian Russia and neighboring countries: Problems and prerequisites for sustainable development] Resp. Ed. Baklanov P. Ya., Tulokhonov A. K. Novosibirsk: SB RAS Publishing House, 2010. 606 p. (In Russ.)

Transport corridors of the Silk Road: the potential for growth of cargo flows through the EEU. St. Petersburg: EDB CIS2018. 74 p. (In Russ.)

Tulokhonov A.K. (2017) Once again on the administrative and territorial structure of Russia. Economist [The Economist]. No. 11. Pp.17-21. (In Russ.)

Tulokhonov A.K. (2012) About the prophets in their homeland (to the 150th anniversary of PA Stolypin). Voprosy ekonomiki [Economics issues]. No. 6. Pp. 152-155. (In Russ.) 